\title{
New insights in gene expression alteration as effect of doxorubicin drug resistance in triple negative breast cancer cells
}

Cristina Alexandra Ciocan-Cartita ${ }^{1 \dagger}$, Ancuta Jurj ${ }^{1 \dagger}$, Oana Zanoaga ${ }^{1}$, Roxana Cojocneanu', Laura-Ancuta Pop', Alin Moldovan', Cristian Moldovan², Alina Andreea Zimta², Lajos Raduly', Cecilia Pop-Bica', Mihail Buse², Liviuta Budisan", Piroska Virag ${ }^{3}$, Alexandru Irimie ${ }^{4,5}$, Sandra Martha Gomes Dias ${ }^{6}$, loana Berindan-Neagoe ${ }^{1,7^{*}}$ and Cornelia Braicu' (10)

\begin{abstract}
Background: Triple negative breast cancer (TNBC) is a heterogeneous disease with aggressive behavior and an unfavorable prognosis rate. Due to the lack of surface receptors, TNBC must be intensely investigated in order to establish a suitable treatment for patients with this pathology. Chemoresistance is an important reason for therapeutic failure in TNBC.

Method: The aim of this study was to investigate the effect of doxorubicin in TNBC cell lines and to highlight cellular and molecular alterations after a long exposure to doxorubicin.

Results: The results revealed that doxorubicin significantly increased the half maximal inhibitory concentration $\left(\mathrm{IC}_{50}\right)$ values at P12 and P24 compared to parenteral cells P0. Modifications in gene expression were investigated through microarray technique, and for detection of mutational pattern was used Next Generation Sequencing (NGS). 196 upregulated and 115 downregulated genes were observed as effect of multiple dose exposure, and 15 overexpressed genes were found to be involved in drug resistance. Also, the presence of some additional mutations in both cell lines was observed.

Conclusion: The outcomes of this research may provide novel biomarkers for drug resistance in TNBC. Also, this activity can highlight the potential mechanisms associated with drug resistance, as well as the potential therapies to counteract these mechanisms.
\end{abstract}

Keywords: Triple negative breast cancer, Doxorubicin, Next-generation sequencing, Microarray, Drug resistance

\footnotetext{
* Correspondence: ioananeagoe29@gmail.com

${ }^{\dagger}$ Cristina Alexandra Ciocan-Cartita and Ancuta Jurj are co-first author with equal contribution.

${ }^{1}$ Research Center for Functional Genomics, Biomedicine and Translational

Medicine, "Iuliu Hatieganu" University of Medicine and Pharmacy,

Cluj-Napoca, Romania

${ }^{7}$ Department of Functional Genomics and Experimental Pathology, "Prof. Dr.

Ion Chiricuta" Oncology Institute, Cluj-Napoca, Romania

Full list of author information is available at the end of the article
}

(c) The Author(s). 2020, corrected publication [2020]. Open Access This article is licensed under a Creative Commons Attribution 4.0 International License, which permits use, sharing, adaptation, distribution and reproduction in any medium or format, as long as you give appropriate credit to the original author(s) and the source, provide a link to the Creative Commons licence, and indicate if changes were made. The images or other third party material in this article are included in the article's Creative Commons licence, unless indicated otherwise in a credit line to the material. If material is not included in the article's Creative Commons licence and your intended use is not permitted by statutory regulation or exceeds the permitted use, you will need to obtain permission directly from the copyright holder. To view a copy of this licence, visit http://creativecommons.org/licenses/by/4.0/. The Creative Commons Public Domain Dedication waiver (http:// creativecommons.org/publicdomain/zero/1.0/) applies to the data made available in this article, unless otherwise stated in a credit line to the data. 


\section{Background}

Triple-negative breast cancer (TNBC) is immunohistochemically defined by the lack of three important receptors: estrogen (ER), progesterone (PR) and human epidermal growth factor receptor 2 (HER2) [1, 2]. TNBC is a less frequent phenotype, being around $15-20 \%$ of all breast cancers. Despite this, TNBC is generally diagnosed in young patients, presenting a high metastatic capacity and an unfavorable prognostic rate [3]. TNBC is a relevant clinical challenge considering that this cancer subtype does not respond to endocrine therapy or other targeted agents $[1,4]$. Meanwhile, conventional chemotherapy and radiotherapy remain the main important alternative for these patients [5].

Chemotherapeutics is widely used as treatment strategy against TNBC tumors. However, the effectiveness of the treatment can be affected by the activation of the resistance related mechanisms [5, 6]. A typical and common treatment used for breast cancer, is represented by doxorubicin (DNA damaging agent) in combination with paclitaxel (microtubule-stabilizing drug) or/and cyclophosphamide [7-9].

The mechanisms of primary or acquired chemoresistance to doxorubicin still remain to be deciphered. Thus, our study is focused on the regulatory pathways responsible for resistance to therapy and possible specific targets that could help optimize patient responses to this drug $[10,11]$. Chemoresistance is correlated with genetic alterations, that can activate pro-survival signaling, DNA damage repair, drug efflux or epithelial-mesenchymal transition [12-14]. The recognition of molecular features responsible for a particular response to chemotherapy, particularly transcriptomics and genetic alterations, proved to have a significant impact on cancer research. These features could be represented by biomarkers for resistance or sensitivity to a particular drug, or specific mechanistic alteration that can be a starting point for overcoming this resistance mechanism [15].

In this study, we developed two doxorubicin-resistant TNBC cell lines (Hs578T/Dox and MDA-MB-231/Dox) by multiple dose exposure of TNBC cells to doxorubicin, followed by evaluation of the alteration at genetic and transcriptomic levels. In this sense, the evaluation of gene expression patterns as effect of multiple dose exposure to doxorubicin was explored. The response of TNBC cell lines (Hs578T and MDA-MB-231) to doxorubicin was examined after exposure to $50 \mathrm{nM}$ doxorubicin for 12 , respectively 24 passages, followed by the evaluation of morphological alterations, along with genetic and transcriptomic patterns.

\section{Materials and methods}

\section{Cell culture and induction of doxorubicin resistance}

In this study, the experiments were performed on triple negative breast cancer (TNBC) cell lines, Hs578T and
MDA-MB-231. The Hs578T cell line was cultured in D-MEM high glucose (D-MEM Gibco ${ }^{\circ}$ ) supplemented with $10 \%$ fetal bovine serum (FBS- Gibco $\left.^{\circ}\right), 2 \mathrm{mML}$ glutamine $\left(\mathrm{Gibco}^{\circ}\right), 1 \%$ MEM Non-Essential Amino Acids Solution (100X, Gibco $\left.{ }^{\circ}\right), 0.01 \mathrm{mg} / \mathrm{ml}$ insulin and $1 \%$ Penicillin-Streptomycin $\left(\right.$ Gibco $\left.^{\circ}\right)$. MDA-MB-231 cell line was cultured in RPMI-1640 (RPMI-1640 Gibco ${ }^{\circ}$ ), supplemented with $10 \%$ fetal bovine serum (FBSGibco $\left.^{\oplus}\right), 2 \mathrm{mM}$ L-glutamine $\left(\mathrm{Gibco}^{\odot}\right)$ and $1 \%$ PenicillinStreptomycin $\left(\mathrm{Gibco}^{\circ}\right)$. Cells were maintained in a humidified atmosphere at $37^{\circ} \mathrm{C}$ with $95 \%$ air and $5 \%$ of $\mathrm{CO}_{2}$ (carbon dioxide). The doxorubicin-resistant TNBC cells were established by multiple dose exposure. The drug concentration used for maintaining the drug resistance of Hs578T/Dox and MDA-MB-231/Dox was $50 \mathrm{nM}$. Cells were treated with this dose for 12 , and respectively 24 passages (Figure S1).

\section{Assessment of doxorubicin sensitivity}

The assessment of the half maximal inhibitory concentration $\left(\mathrm{IC}_{50}\right)$ of the parental (Hs578T and MDA-MB-231) and drug-resistant cells (Hs578T/Dox and MDA-MB-231/ Dox) was performed through MTT assays in order to evaluate the inhibitory effects on cell proliferation. In brief, at a seeding density of $1.2 \times 10^{4}$ cells/well, the cells were plated in 96-well plates and treated with stepwise concentrations of doxorubicin. Cellular viability and cytotoxicity were evaluated after $48 \mathrm{~h}$ by adding $1 \mathrm{mg} / \mathrm{ml}$ MTT solution and withdrawn after $2 \mathrm{~h}$ of incubation. As a final step, $100 \mu \mathrm{l}$ of dimethyl sulfoxide was added in each well and the absorbance was detected at $570 \mathrm{~nm}$ using a BioTek microplate reader.

\section{Cytoskeletal evaluation}

Morphological traits were evaluated through confocal microscopy using specific dyes for actin-filaments (Phalloidin, green dye) and nucleus (DAPI, blue dye). Modifications that occur post-therapy were evaluated at passage P0, P12 and P24 in order to increase the effects of doxorubicin on both TNBC cell lines. For this evaluation, treated cells were fixed and permeabilized with $4 \%$ paraformaldehyde, respectively $0.5 \%$ Triton X. Moreover, treated cells were stained with $200 \mathrm{nM}$ Phalloidin dye for $30 \mathrm{~min}$ followed by an additional $1 \mathrm{~min}$ incubation with DAPI dye. The coverslips were mounted with $90 \%$ glycerol. The fluorescence microscopically images were captured using UPLSAPO40X2 (NA:0.95, Olympus Japan).

\section{DNA fragmentation using comet assay}

DNA fragmentation using Comet assay as effect of serial exposure to doxorubine (P0, P12 and P24) on Hs578T and MDA-MB-231 was evaluated using the alkaline single cell gel electrophoresis assay or Comet assay, by Tice' protocol as described previously [16, 17]. 
Genetic alteration evaluation using next-generation sequencing panel on ion torrent

DNA was extracted using the Purelink Genomic DNA minikit following the manufacturer instruction. We used two triple negative breast cancer cell lines (HS578T and MDA-MB-231) samples that were treated with doxorubicin. DNA was extracted from samples at passage 0 (P0), 12 (P12) and 24(P24) after treatment. The DNA concentration was quantified using NanoDrop and were obtained concentrations between 54.19-115.4 ng/ $\mu \mathrm{l}$.

$20 \mathrm{ng}$ of DNA were used for sequencing using the Ion AmpliSeq Cancer Hotspot Panel v2 (ThermoFisher Scientific) and the Ion AmpliSeq Library 2.0 kit (ThermoFisher Scientific). The Ion AmpliSeq Cancer Hotspot Panel v2 consists of primers for hotspot evaluation in the following genes: $A B L 1, A K T 1, A L K, A P C, A T M$, BRAF, CDH1, CDK2A, CSF1R, CTNNB1, EGFR, ERBB2, ERBB4, EZH2, FBXW7, FGFR1, FGFR2, FGFR3, FLT3, GNA11, GNAQ, GNAS, HNF1A, IDH1, IDH2, JAK2, JAK3, KDR, KIT, KRAS, MET, MLH1, MPL, NOTCH1, NPM1, NRAS, PDGFRA, PIK3CA, PTEN, PTPN11, RB1, RET, SMAD4, SMARB1, SMO, STK11, TP53, VHL. After library preparation, the samples were purified using the AMpure XP Beads (Bechman Coulter). The purified libraries were quantified using the fluorometer Qubit 2.0 and the Qubit HS DNA kit. For template synthesis, libraries were diluted to $100 \mathrm{pM}$ and multiplex for libraries on Ion 316 Chip (ThermoFisher Scientific). The sequencing process was performed on the Ion Torrent PGM Machine (ThermoFisher Scientific) using the Ion PGM HI-Q Sequencing 200 kit. The data obtained after sequencing were analyzed using the Torrent Suit 5.6 and Ion Reporter 5.6 software for data trimming, alignment and variant calling. The obtained variants were filtered using the following conditions: $p$ value $\leq 0.05$, coverage $\geq 500$.

\section{Gene expression microarray evaluation}

Total RNA extraction, from TNBC treated and untreated cells, was performed using TriReagent (Invitrogen) and purified using RNeasy miniprep kit (Qiagen) according to the manufacturer's instruction. The RNA concentration and quality were evaluated using Nanodrop-1000 spectrophotometer (Thermo Scientific) and Bioanalyzer (RIN $\geq 7$ ).

The alteration of gene expression pattern was done using Agilent microarray technology using SurePrint G3 Gene Expression Microarrays (8x60k), covering 26,083 genes and 30,606 lncRNA transcripts starting from $200 \mathrm{ng}$ of total RNA following the Agilent standard protocol. After hybridization step, $17 \mathrm{~h}$ at $65^{\circ} \mathrm{C}$ at $10 \mathrm{rpm}$, the arrays were washed and scanned with the Agilent scanner. Probe features were extracted from the microarray scan data using Feature Extraction software (Agilent Technologies).

\section{qRT-PCR data validation}

Validation of the microarray results was done using RTPCR technique on both TNBC cells. In this regard, genes involved in drug resistance mechanisms were selected (IL-6, CLU, JUNB and TNSF10). GAPDH and B2M were used as reference genes. In brief, $1000 \mathrm{ng}$ of total RNA was reversed transcribed into cDNA using High Capacity cDNA Reverse Transcription Kit (Applied Biosystems) and amplified using SYBR Select Master Mix (Applied Biosystems) on ViiA ${ }^{\mathrm{m}} 7$ System (10 $\mu \mathrm{l}$ reaction volume in 384-well plate). Relative quantification was done using the $2^{-\Delta \Delta C T}$ method.

\section{CXCL1, IL-6 and TNF-a quantification in cell culture medium}

The expression levels of CXCL1 released in the cell culture medium were detected by ELISA using the Human CXCL1 DuoSet ELISA (R\&D System, cat no. DY275). For TNF- $\alpha$ was used Human TNF- $\alpha$ DuoSet ELISA (R\&D System, cat no. D210), and IL-6 DuoSet ELISA (R\&D System, cat no. DY206) for IL-6 quantification along with DuoSet Ancillary Reagent Kit 2 (R\&D Systems, cat no. DY008).

\section{Statistical analysis}

Resulted data were expressed as mean \pm SD (standard deviation). The difference between experimental conditions and controls were analyzed using t test (statistically significant was considered $p<0.05)$. Statistical analyses were carried out using GraphPad Prism version 6, Panther, Venny and String 8.0 free version software.

\section{Results}

\section{Cellular viability and doxorubicin assessment on TNBC cell lines}

The effect of doxorubicin on TNBC cell lines was investigated in control cells (P0), cells with multiple dose exposure for 12 serial passages (P12), respectively 24 passages (P24), with doxorubicin between 0 and $100 \mu \mathrm{M}$. The MTT values are presented as \% of control in relation with the $\log$ (concentration, $\mu \mathrm{M}$ ) (Fig. 1a). $\mathrm{IC}_{50}$ concentrations were calculated at each time point using GraphPad Prism software. According to $\mathrm{IC}_{50}$ concentrations, important modifications in antiproliferative activity of treated TNBC cells were observed. The increased values of $\mathrm{IC}_{50}$ corresponding for passage P12 respectively P24 are related to the activation of drug resistance mechanisms.

Further, morphological traits were investigated as a result of a long-term exposure to doxorubicin therapy. In Fig. $1 \mathrm{~b}$ the significant alterations occurred in cellular morphology are highlighted through the presence of modifications in actin-filaments and nucleus structure. In the control group, both cell lines exhibited normal 
$(A)$

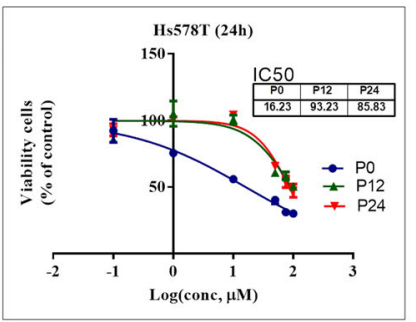

(B)

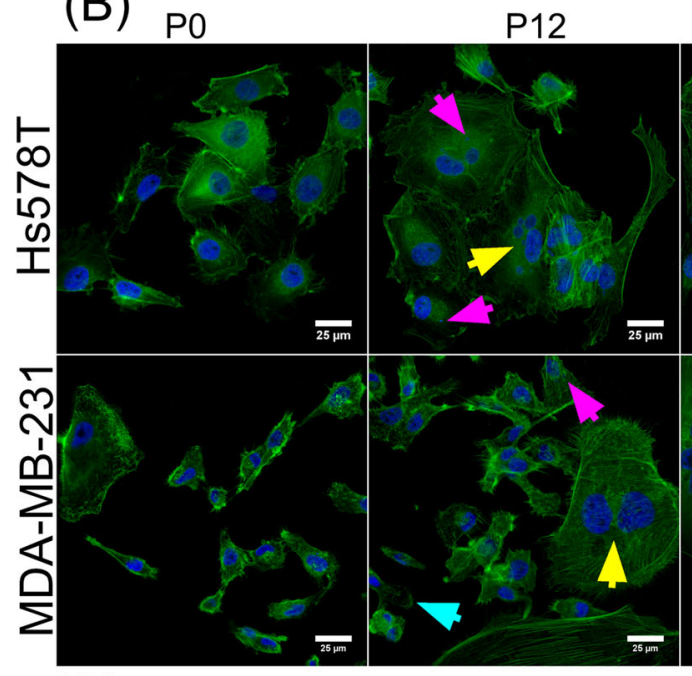

(C) $\mathrm{PO}$

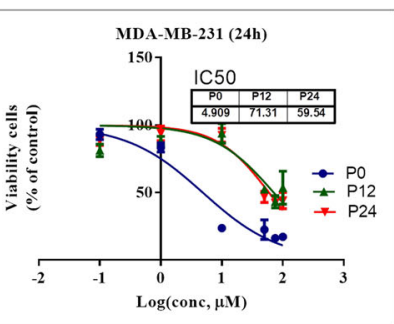

P24

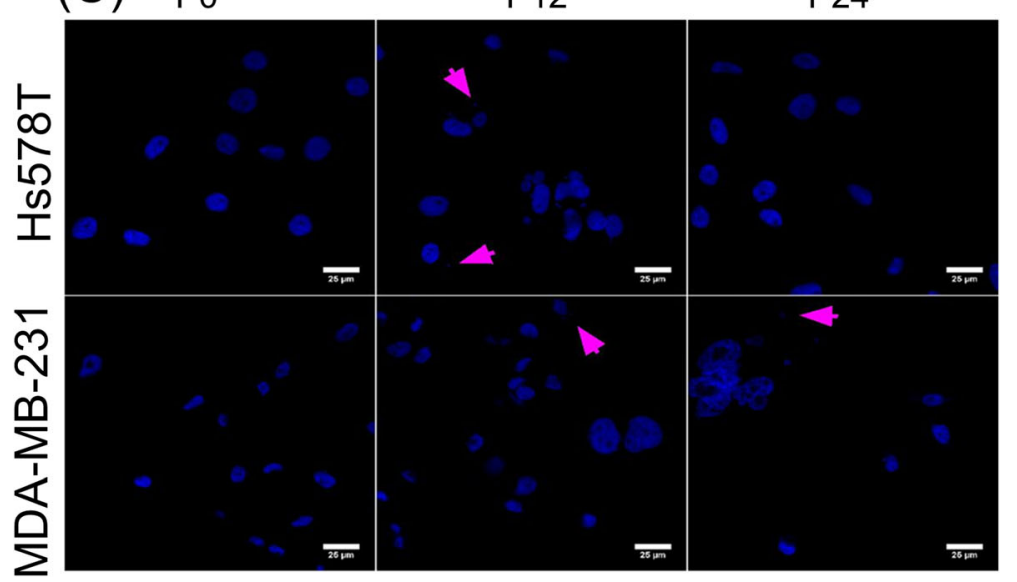

Fig. 1 The effects on cell proliferation and cell morphology after doxorubicin-multiple dose exposure. a The antiproliferative effects on TNBC cell lines, Hs578T and MDA-MB-231, measured using MTT assay using stepwise concentrations of doxorubicin $(0.1,1,10,50,75,100 \mu M)$ to determine the $I_{50}$ values at P0, P12 and P24; data are represented as $\log (\mathrm{conc}, \mu \mathrm{M})=\log [$ concentration of doxorubicin, $\mu \mathrm{M}]$ (mean $\pm S D, n=3)$. $\mathbf{b}$ The evaluation of morphological traits after doxorubicin exposure on TNBC cell lines (P12 and P24) though confocal microscopy. Actin filaments were staining using Phalloidin dye and nucleus was staining using DAPI dye. Scale represents $25 \mu \mathrm{m}$. Images were captured with 60x oil immersed objective (PLAPON60xOSC2,1.4 NA). c Alteration of nuclear cell morphology, evaluated by DAPI staining on blue channel (405 nm excitation). Magenta arrows represent the formation of the micronucleus, yellow arrows point multinucleate/polynuclear cells and blue arrows point cytoskeleton damage

features, meanwhile treated TNBC cells presented modifications in their structure. After doxorubicin exposure both cells lines started to exhibit alterations in their structure suggesting the activation of apoptotic processes, as compared to the control cells (P0). Thereby, the presence of micronucleus (magenta arrows), cytoskeleton damage (blue arrow) and polynuclear cells (yellow arrow) were showed at P12 and 24 in Hs578T and MDA-MB-231 cells, respectively after a prolonged exposure with doxorubicin. No such alterations were observed in P0 cells. The micronucleus alteration is detailed in Fig. 1c, by nuclear DAPI staining, on blue channel. Also, MDA-MB-231 cells 
treated at passage P12 and P24 exhibited giant cells suggesting that doxorubicin induces cell death through mitotic catastrophe where cells become multinucleated and enlarged, as well as loss of plasma membrane integrity. The alterations observed in Hs578T P24 were associated with stress fibers that are related to the EMT process and to the mesenchymal traits, proving that doxorubicin treatment activates more aggressive cells.

\section{DNA fragmentation using comet assay}

DNA breaks (single or double strand breaks) leads to a relaxation of the DNA, migration under electric field creating comet tails. DNA cross-links do not permit DNA unwinding. Thus, when they are produced, the DNA does not migrate and comet tails are shorter. The treatment with doxorubicin led to DNA lesions which were observed under the microscope as comet tails of different grades, being described as lesion scores (LS) and tail factor (TF), as presented in Fig. 2.

DNA breaks form comet tails with different lengths depending on the severity of the lesions. In our experiment the exposure to doxorubicin did not produce significant difference between the LS and TF, compared to control cells (P0) in both cell lines, except for the Hs578T cells at P12, where the LS and TF values were lower than the control cells, probable as effect of DNA repair mechanism activation. This phenomenon was not retrieved at P24, meaning that DNA breaks were similar as in control P0 cells.

\section{Identification of mutation signatures in drug-resistant TNBC cells}

We analyzed the mutation patterns for both TNBC cell lines, Hs578T and MDA-MB-231, at passage P0, P12 respectively P24. Figure $3 \mathrm{a}$ and $\mathrm{b}$ present the mutations identified in each gene for each passage. In the case of Hs578T cell line, we observed that all three passages present the same mutations signature, with two exceptions; mutation c. $215 \mathrm{C}>\mathrm{G}$ in TP53 gene presented in both passages, P12 respectively P24, as well as the presence of mutation c.4732_4734delGTG in NOTCH1 gene presented in passage P24. Also, the mutation presented in TP53 gene is associated with drug response in clinical database ClinVar (Fig. 3). Meanwhile, the mutation observed in NOTCH1 gene exhibits unknown clinical implication (based on ClinVar or FATHMM data base) but is already described in the public databases dbSNP and COSMIC, the clinical significance of this mutation remains to be demonstrated. For MDA-MB-231 cell line, the mutation signatures are similar for passage P12 and P24. For passage P0 (used as control) we found only the presence of three mutated genes, BRAF, KRAS, TP53.

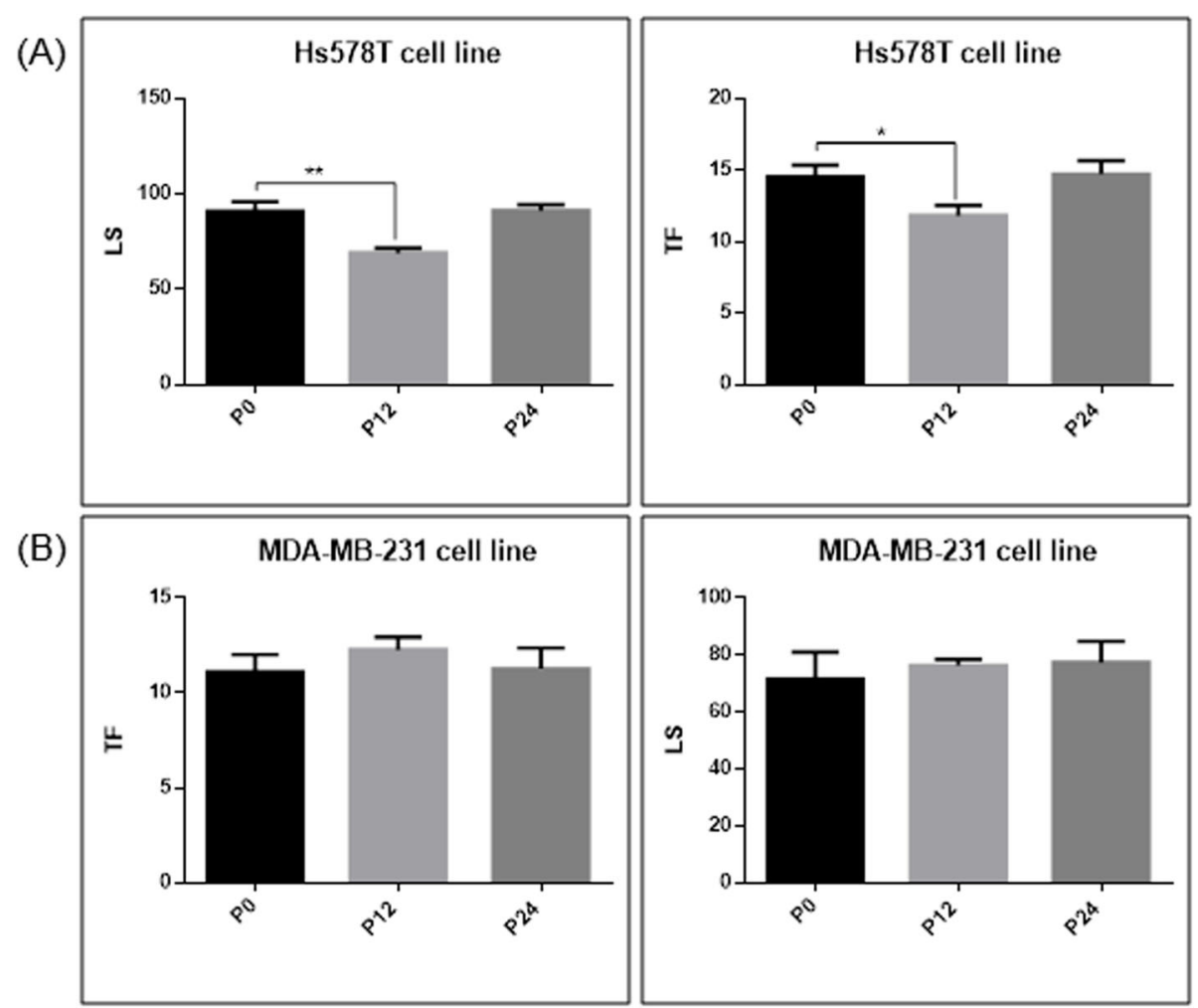

Fig. 2 LS and TS calculated for the treatment with doxorubicine serial passages (P0: control cells, P12 and P24 a Hs578T cells and b MDA-MB-231 cells 


\begin{tabular}{|c|c|c|c|c|c|c|c|c|c|c|c|c|c|c|c|}
\hline \multicolumn{16}{|l|}{ (A) } \\
\hline \multirow[b]{2}{*}{ Mutation } & \multicolumn{15}{|c|}{ Mutation } \\
\hline & \multicolumn{2}{|c|}{\begin{tabular}{c|c|c}
$c .421+58$ \\
$\mathrm{~A}>\mathrm{G}$ ERBB4 \\
\end{tabular}} & \multicolumn{2}{|c|}{\begin{tabular}{|c|} 
c. $352+40 \mathrm{~A}>\mathrm{G}$ \\
$\mathrm{PIK} 3 \mathrm{CA}$
\end{tabular}} & $\begin{array}{l}\text { c. } 3849-24 \\
\text { C }>\text { A KDR }\end{array}$ & $\begin{array}{c}c .798+54 \\
G>A \text { KDR }\end{array}$ & \begin{tabular}{|c|c} 
c." 37 delT \\
CSF1A
\end{tabular} & \multicolumn{2}{|c|}{$\begin{array}{l}\text { c."*35instA } \\
\text { CSF1A }\end{array}$} & $\begin{array}{c}\mathrm{c} .35 \mathrm{G}>\mathrm{A} \\
\mathrm{HRAS} \\
\end{array}$ & $\begin{array}{c}\text { c. } 817 \mathrm{~A}>\mathrm{G} \\
\text { HNF1A }\end{array}$ & $\begin{array}{c}c .1310-3 \\
T>\text { C FLT3 } \\
\end{array}$ & $\begin{array}{c}c .469 \mathrm{G}>\mathrm{T} \\
\text { TP53 } \\
\end{array}$ & $\begin{array}{l}\mathrm{c} .215 \mathrm{C}>\mathrm{G} \\
\mathrm{TP53}\end{array}$ & $\begin{array}{c}\text { c. } 4732 \_4734 \\
\text { delGTG NOTCH1 } \\
\end{array}$ \\
\hline \multicolumn{16}{|l|}{ HS578T p0 } \\
\hline \multicolumn{16}{|l|}{ HS578T p12 } \\
\hline \multicolumn{16}{|l|}{ HS578T p24 } \\
\hline \multicolumn{11}{|l|}{ (B) } & \multicolumn{5}{|l|}{ (C) } \\
\hline \multirow{3}{*}{ Sample } & \multicolumn{10}{|c|}{ Mutation } & & \multicolumn{4}{|c|}{ drug response } \\
\hline & & $G>T$ & $G>A$ & $\mathrm{G}>\mathrm{A}$ & $A>G$ & \begin{tabular}{l|l}
$G>A$ & $c$
\end{tabular} & c. $* 37 \mathrm{deIT}$ & c.*35inst & $C>G$ & $\mathrm{C}>\mathrm{T}$ & & \multicolumn{4}{|c|}{ benign } \\
\hline & \multicolumn{15}{|c|}{ likely pathogenic } \\
\hline \multicolumn{3}{|c|}{ MDA-MB-231 p12 } & & & & & & & & & & \multicolumn{4}{|c|}{ pathogenic } \\
\hline \multicolumn{3}{|c|}{ MDA-MB-231 p24 } & & & & & & & & & & \multicolumn{4}{|c|}{ variant of unknown significance } \\
\hline
\end{tabular}

Fig. 3 Mutation patterns in TNBC cells evaluated by next generation sequencing using lon Torrent PGM Machine and lon AmpliSeq Cancer Hotspot Panel. a Mutations identified in the HS578T samples; b Mutations identified in the MDA-MB-231 samples; $\mathbf{c}$ type of mutation legend: blue- drug response, green- benign, orange-likely pathogenic, red- pathogenic, purple- variance of unknown significance

The mutated genes in TNBC cell lines have both intronic and exonic localization. TP53 has a very low activity in the analyzed cell lines. As can be observed in the IntoGene software, the main driver genes in breast cancer are TP53 and PIK3CA. Also, by reevaluating the CliVar database we observed that mutations of ERBB4 $($ c. $421+58 \mathrm{~A}>\mathrm{G})$, PIK3CA (c.352 + $40 \mathrm{~A}>\mathrm{G})$ and KDR (c.3849-24C $>$ A) have unknown significance (Fig. 3). Also, the TP53 c.469C > T was observed in some studies on breast cancer and classified as likely pathogenic or pathogenic $[18,19]$. The TP53 c.839G > A mutation was also observed in early onset familial prostate cancer and classified as likely pathogenic [20].

\section{Identification of altered genes and IncRNAs expression} profiles in TNBC cell lines as effect of doxorubicin therapy In the present investigation of expression profile was used Agilent microarray technology (8x60k slides) to identify the altered transcriptomics pattern as response to multiple dose exposure to doxorubicin therapy. Thus, it was possible the identification of the most relevant altered genes in TNBC cell lines, as well as in passage P12, respectively P24, versus control cells (P0). A cut-off value for FC of \pm 2 and $p \leq 0.05$ was selected to determine the modifications occurred in transcriptomic patterns.

Significant alteration on gene and lncRNAs-expression profiles for both cell lines were identified, indicating the presence of 2035 altered genes (966 overexpressed and 1069 downregulated) and 1441 lncRNAs (534 overexpressed and 907 downregulated) on Hs578T cells at P12 versus P0; 1071 differentially expressed genes (510 overexpressed and 561 downregulated) and 835 differentially expressed lncRNAs (412 overexpressed and 423 downregulated) on MDA-MB231 cells were identified at $\mathrm{P} 12$ versus $\mathrm{P} 0$.
Moreover, the expression profiles of 2085 altered genes (1181 overexpressed and 904 downregulated) and 1517 lncRNAs (732 overexpressed and 785 downregulated) on Hs578T cells P24 versus P0, as well as 1215 genes (629 overexpressed and 586 downregulated) and 940 lncRNAs (344 overexpressed and 596 downregulated) between MDA-MB-231 cells at P24 versus P0 were observed. The data are summarized in Tables 1 and 2, where top 20 altered transcripts on each experimental setting are presented. The heatmap for this data is presented in Fig. 4a and b. We overlapped the genes and IncRNAs profiling data obtained from the datasets mentioned above and the Venn diagram represented in Fig. 4c-j. The common genes and lncRNAs were altered in both TNBC cell lines in all three passages (P0, P12 respectively P24). In Fig. 5 are presented the common genes/lncRNAs in Hs578T and MBA-MB-231 cells. In this regard, we can observe the presence of a high number of genes/lncRNAs identical in both cell lines, transcripts involved mainly in modulation of different biological processes.

\section{Pathway analysis in TNBC cell lines}

The genes with an altered expression level were input into specialized software in order to obtain the important biological processes activated after the exposure to doxorubicin. Panther software highlights the main altered biological functions based on the genes signature from the TNBC cell lines at passage P12, respectively P24. Therefore, 10 relevant biological processes were identified for P12 and P24 as can be observed in Fig. 6. Moreover, the biological processes between genes with down- or upregulated expression profile in P12 and P24 conditions are similar. The altered genes are mainly 
Table 1 Overview of the genes with an altered expression level as effect of exposure to 12 serial doses of doxorubicin (P12), respectively 24 serial doses (p24) versus control cells (P0), on Hs578T and MDA-MB-231, considering a cut-off value for FC \pm 2 and $p$-value $\leq 0.05$

\begin{tabular}{|c|c|c|c|c|}
\hline Cell line & Analysis & RNA species & Upregulated & Downregulated \\
\hline \multirow[t]{4}{*}{$\mathrm{Hs578T}$} & P12 versus P0 & Coding Genes & 966 & 1069 \\
\hline & & IncRNAs & 534 & 907 \\
\hline & P24 versus P0 & Coding Gene & 1181 & 904 \\
\hline & & IncRNAs & 732 & 785 \\
\hline \multirow[t]{4}{*}{ MDA-MB-231 } & $P 12$ versus $P 0$ & Gene & 510 & 561 \\
\hline & & IncRNAs & 412 & 423 \\
\hline & $P 24$ versus $P 0$ & Gene & 629 & 586 \\
\hline & & IncRNAs & 344 & 596 \\
\hline
\end{tabular}

Table 2 Top 20 most abundant altered genes and IncRNAs as effect of exposure to 12 serial doses of doxorubicin (P12), respectively 24 serial doses (p24) on both TNBC cell lines, Hs578T and MDA-MB-231

\begin{tabular}{|c|c|c|c|c|}
\hline Cell line & Analysis & RNA species & Upregulated & Downregulated \\
\hline \multirow[t]{4}{*}{$\mathrm{Hs578T}$} & \multirow[t]{2}{*}{$P 12$ versus $P 0$} & Gene & $\begin{array}{l}\text { FOS, FOSB, PCSK2, RCSD1, CXCL2, EGR1, SLC12A7, } \\
\text { CXCL2, CXCL3, KIR2DS4, IL6, PKNOX2, IFITM1, } \\
\text { CXCL8, SLC14A1, MX1, IFI27, IFITM1, DRD1, OAS1 }\end{array}$ & $\begin{array}{l}\text { LCP1, HLA-DPB1, NCAM1, LPP, HAPLN2, WDR76, } \\
\text { TRA2A, RHOJ, SH3GL3, ZBTB32, C3AR1, TAS2R30, } \\
\text { CCDC177, PDE8B, FEM1A, CLDN10, KRT83, } \\
\text { UTP11L, GALNT14, YIF1B }\end{array}$ \\
\hline & & IncRNA & $\begin{array}{l}\text { Inc-ARRDC3-1, C8orf4, Inc-AC092327.1-3, } \\
\text { LINC01082, LINC01016, LOC152286, } \\
\text { LOC100506474, C1 orf167, LOC100133669, } \\
\text { LOC101928093, FER1L4, LOC100240735, FENDRR, } \\
\text { MRVI1-AS1, XLOC_I2_012847, CA5B, LINC01431, } \\
\text { LOC100506098, InC-EPSTI1-3, SNORD114-2 }\end{array}$ & $\begin{array}{l}\text { TMEM200C, XLOC_I2_015885, RNA28S5, } \\
\text { RNA18S5, Inc-CDKAL1-1, Inc-ANKRD53-1, } \\
\text { TMPRSS4-AS1, Inc-C12orf49-2, SNRNP40, } \\
\text { LOC441268, Inc-RASA1-3, LINC00271, } \\
\text { LOC102031319, InC-VPS4A-1, ZNF385D-AS2, } \\
\text { Inc-TSC22D1-1, LOC100129940, Inc-CTBP1-1, } \\
\text { HAAO, Inc-ANKRD11-2 }\end{array}$ \\
\hline & \multirow[t]{2}{*}{$P 24$ versus $P 0$} & Gene & $\begin{array}{l}\text { FOS, FOSB, PCSK2, IDO1, SLC12A7, ATF3, EGR1, } \\
\text { CXCL2, SLC14A1, DRD1, ATF3, RCSD1, BMP7, } \\
\text { NR4A2, COLEC12, GABRA2, ACKR3, NR4A3, CES1 }\end{array}$ & $\begin{array}{l}\text { LCP1, NAP1L3, NR0B1, NCAM1, HLA-DPB1, } \\
\text { KRT83, FAM133A, NEFM, GALNT14, ST6GAL2, } \\
\text { DOK5, MAGED4B, LMO7DN, SULT6B1, CILP, } \\
\text { SH3GL3, EPB41L4A, SRD5A2, ITM2A, JPH1 }\end{array}$ \\
\hline & & IncRNA & $\begin{array}{l}\text { CYP2S1, Inc-ARRDC3-1, Inc-AC092327.1-3, C8orf4, } \\
\text { LINC01082, Inc-GABRA2-1, LUCAT1, CYP2S1, } \\
\text { LOC101928093, Inc-EPSTI1-3, InC-KLHDC10-2, } \\
\text { FENDRR, Inc-ENPP2-1, CA5B, XLOC_I2_013293, } \\
\text { LINC00524, LOC100506098, LOC344887, FENDRR, } \\
\text { LOC101928582 }\end{array}$ & $\begin{array}{l}\text { LOC100507377, SP3P, C16orf97, CAMK1D, } \\
\text { LOC101928942, C1orf220, LINC01197, } \\
\text { LOC101927115, Inc-CXCL2-1, InC-MBP-1, } \\
\text { LOC284009, Inc-AC078802.1-1, MCM3AP-AS1, } \\
\text { InC-RASA1-3, MKL2, InC-PYDC2-1, InC-ZNF91-2, } \\
\text { HAAO, FLJ11710LOC100132495 }\end{array}$ \\
\hline \multirow[t]{4}{*}{ MDA-MB-231 } & \multirow[t]{2}{*}{$P 12$ versus $P 0$} & Gene & $\begin{array}{l}\text { CXCL2, CCL20, CSF3, FOSB, NR4A3, NR4A2, FOS, } \\
\text { CSF2, LCN2, IL6, NPPB, ATF3, HES1, IL1A, CXCL1, } \\
\text { CXCL3, C3, ATF3, SAA2, IL1B }\end{array}$ & $\begin{array}{l}\text { THBS2, HTR1F, ATP8A1, SSX4B, SSX1, BEX5, } \\
\text { POU3F2, SNCAIP, TIE1, SEPP1, SHISA3, PCSK5, } \\
\text { PPP2R2C, DMD, CHRDL1, KLHL10, PELI2, CHRM2, } \\
\text { ATP11AUN, CMKLR1 }\end{array}$ \\
\hline & & IncRNA & $\begin{array}{l}\text { RNA5-8S5, LOC729451, C1QTNF1-AS1, } \\
\text { Inc-MTHFD2L-1, C40rf26, LOC102724910, } \\
\text { LOC101928353, MALAT1, Inc-FLYWCH2-1, } \\
\text { LINC00996, Inc-FGF9-1, C15orf48, Inc-ASMT-5, } \\
\text { LOC101926959, XLOC_I2_015438, SAT1, } \\
\text { Inc-DZIP1-3, NAMPT, HOXB-AS1, Inc-IL6-2 }\end{array}$ & $\begin{array}{l}\text { Inc-IL1R2-1, Inc-POTEB-5, Inc-PRKD1-2, } \\
\text { LOC643201, Inc-C140rf37-1, XLOC_I2_008221, } \\
\text { SMEK3P, EPB41L4A-AS2, TMEM71, SSX8, } \\
\text { XLOC_I2_012323, ZNF503-AS2, LOC101929484, } \\
\text { InC-RP1-177G6.2.1-2, TMEM92-AS1, InC-GNLY-1, } \\
\text { LOC101928710, LOC643201, InC-MAFB-1, } \\
\text { LOC101929395 }\end{array}$ \\
\hline & \multirow[t]{2}{*}{$P 24$ versus $P 0$} & Gene & $\begin{array}{l}\text { FOSB, FOS, CXCL2, CCL20, IL6, CSF3, ATF3, NR4A3, } \\
\text { NR4A2, NPPB, CXCL3, NKX2-1, LCN2, CSF2, EGR1, } \\
\text { EGF4, HES1, C1QTNF1, ZFP36, MUC4 }\end{array}$ & $\begin{array}{l}\text { THBS2, HTR1F, CHRDL1, ATP8A1, CMKLR1, SSX1, } \\
\text { SSX4B, PCSK5, PAGE2B, PAGE2, POU3F2, PELI2, } \\
\text { SEPP1, KIRREL3, COX7B2, TIE1, BEX5, KLHL10, } \\
\text { GPR158, MMP1 }\end{array}$ \\
\hline & & IncRNA & $\begin{array}{l}\text { XLOC_I2_012748, Inc-MTHFD2L-1, LOC729451, } \\
\text { Inc-ME3-1, MALAT1, InC-ASMT-5, C11 orf53, } \\
\text { Inc-FGF9-1, LOC102724910, C1QTNF1-AS1, } \\
\text { Inc-ANKRD10-1, LOC101926940, SNORD36B, } \\
\text { HOXB-AS1, LOC100133669, Inc-UMPS-2, } \\
\text { LOC102724434, XLOC_I2_013125, } \\
\text { XLOC_I2_015438, C11 orf96 }\end{array}$ & $\begin{array}{l}\text { Inc-POTEB-5, Inc-PRKD1-2, LOC101928942, } \\
\text { XLOC_I2_012323, LOC643201, Inc-PTPRG-1, } \\
\text { LINC01197, Inc-FOXL1-2, LOC101928915, } \\
\text { LOC101928710, EPB41L4A-AS2, } \\
\text { XLOC_I2_008783, LOC643201, SSX8, } \\
\text { LOC100128242, LOC101928413, } \\
\text { Inc-RP11-712 L6.5.1-2, Inc-BLID-1, } \\
\text { Inc-CCDC140-5, Inc-JPH4-1 }\end{array}$ \\
\hline
\end{tabular}




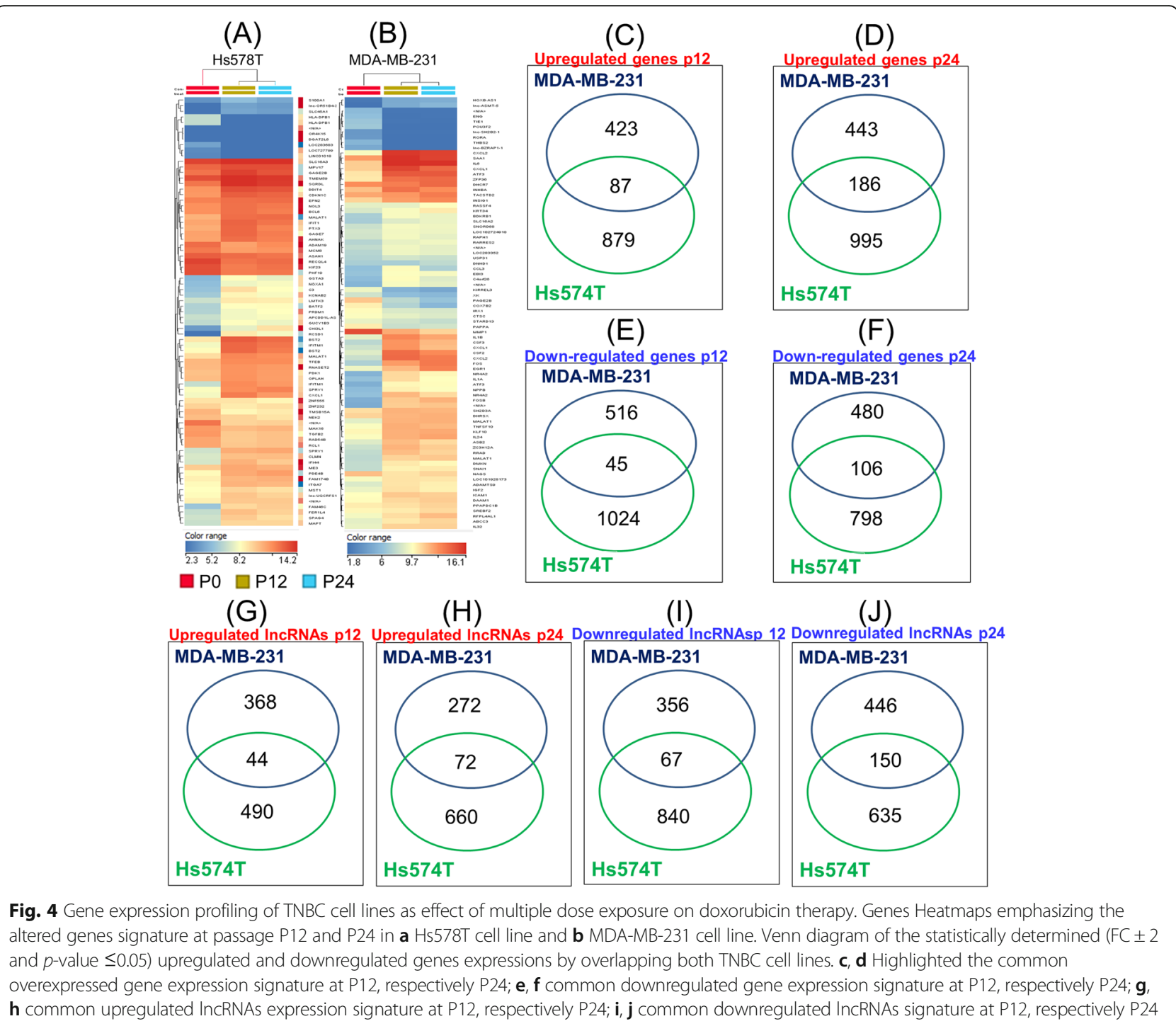

involved in cell proliferation and reproduction, and immune system processes.

Using Venn diagram, the main common up- and downregulated genes between P12 and P24 in same cell lines were highlighted (Fig. 7a). The altered up- and downregulated genes were used to generate graphical representation of molecular networks using String software, which displays the specific interactions between transcripts (Fig. 7b). The altered genes critically regulated progression and cell fate by activation of tremendous processes such as TNF signaling pathway or cytokinecytokine receptor interaction.

Altered genes can regulate essential processes responsible for cancer development. Therefore, an additional gene enrichment analysis using GOrilla software presents the involvement of this alterations in different molecular functions proving that doxorubicin has intricate features on nucleic acid binding activity and particular
DNA binding. This gene enrichment analysis highlighted the fact that Hs578T cell line (Fig. 8a) exhibits more altered processes compared to MDA-MB-231 cell line (Fig. 8b).

\section{Construction of a gene expression network involved in drug resistance}

Despite important progress in cancer treatment, acquired resistance to chemotherapeutic drugs still remain a major obstacle in patient treatment and overall outcome. Anticancer drug resistance is activated via numerous mechanisms, and microarrays technique offer a new approach to analyze cellular pathways involved in drug resistance mechanisms being used to predict the unexpected side effects.

Using Venn diagram, we overlapped and highlighted the common genes between both TNBC cell lines at passage P12 and P24, and drug resistance genes list (list 


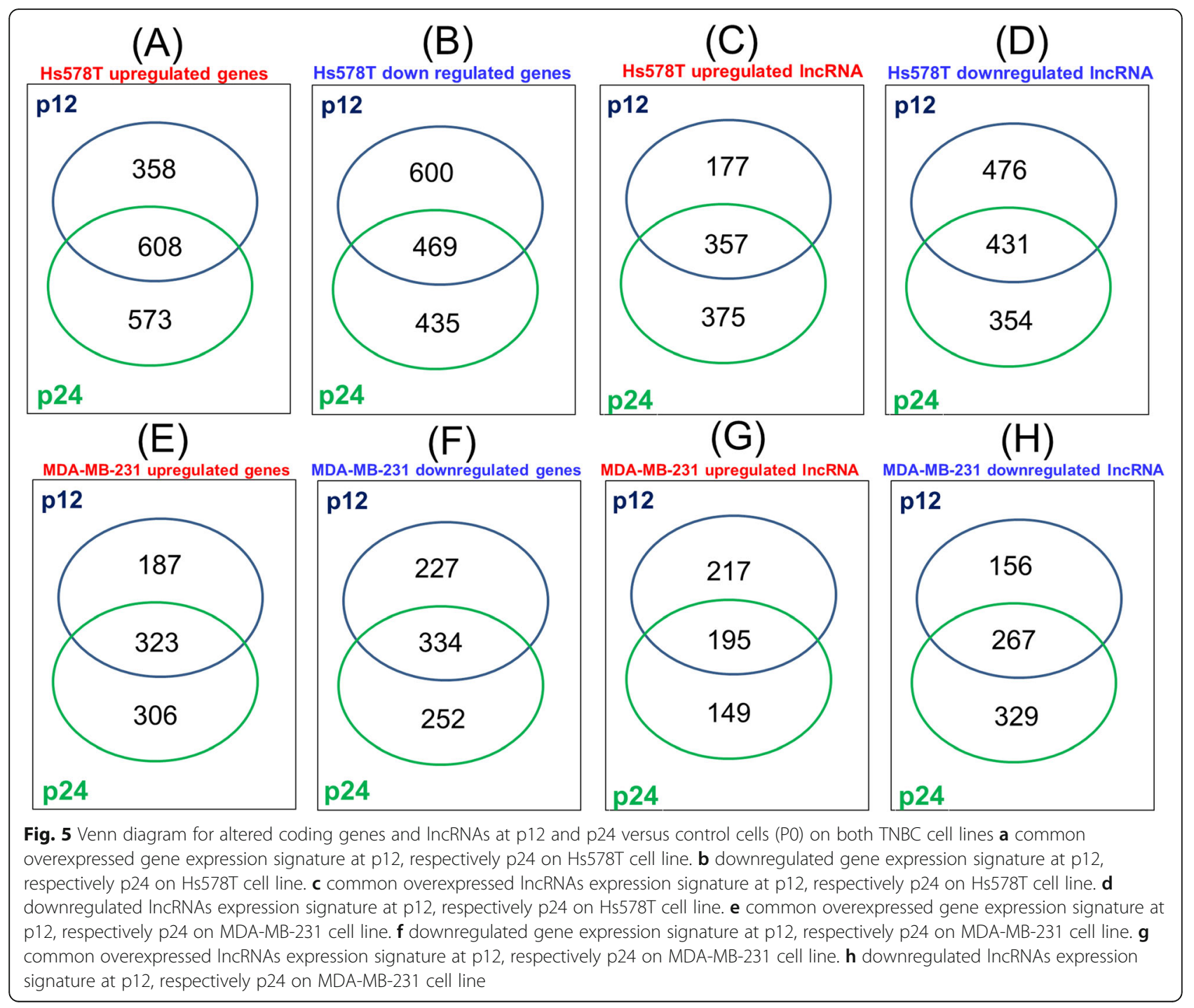

downloaded from NCBI). This overlapping analysis identified 15 genes with a significant involvement in drug resistance mechanisms. Between the 15 genes we identified also $A B C C 3$ and $A B C C 6$, members of the superfamily $\mathrm{ABC}$ transporters. Through String software, the interaction network between common genes involved in drug resistance highlighted the JUNB, CLU, IL-6, TNFSF10 genes as important regulators involved in processes including invasion/metastasis, apoptosis and resistance (Fig. 9).

\section{Validation of genes involved in drug resistance by RT-PCR technique}

The calculation of gene expression FC used the $\Delta \Delta C_{\mathrm{T}}$ method and B2M and GAPDH as the housekeeping gene (Fig. 10). In this section, genes including $I L-6, C L U$, $J U N B$ and TNFSF10 were analysed in both TNBC cell lines, specifically for each passage. In $\mathrm{Hs} 578 \mathrm{~T}$ cell line, the expression levels for $I L-6(p=0.0382)$ and TNSFS10 $(p=0.0368)$ are statistically significant in $\mathrm{P} 12$ group compared to P0 group. Regarding the CLU gene, the relative expression level is slightly overexpressed, meanwhile $J U N B$ gene exhibits no alteration level compared to control group. In the case of P24, the relative expression levels are statistically increased compared to P0 group for IL-6 ( $p=0.0453), C L U(p=0.0181)$, JUNB $(p=0.0083)$ and TNFSF10 ( $p=0.0005)$. In MDA-MB-231 cell line, we observed that the gene expression profile for the selected genes is statistically overexpressed in P12, respectively P24 group compared to P0 group IL-6 ( $p=0.0065, p=0.0020)$, $C L U(p=0.0235, p=0.0017), J U N B(p=0.0051)$ and TNFSF1O $(p=0.0012, p<0.0001)$. Regarding JUNB gene, the relative gene expression level is slightly increased but not statistically significant in P12 group compared to control group (P0).

CXCL1, IL-6 and TNF-a protein quantification using ELISA As additional validation step was asses the evaluation of CXCL1, IL- 6 and TNF- $\alpha$ released for cell culture after 


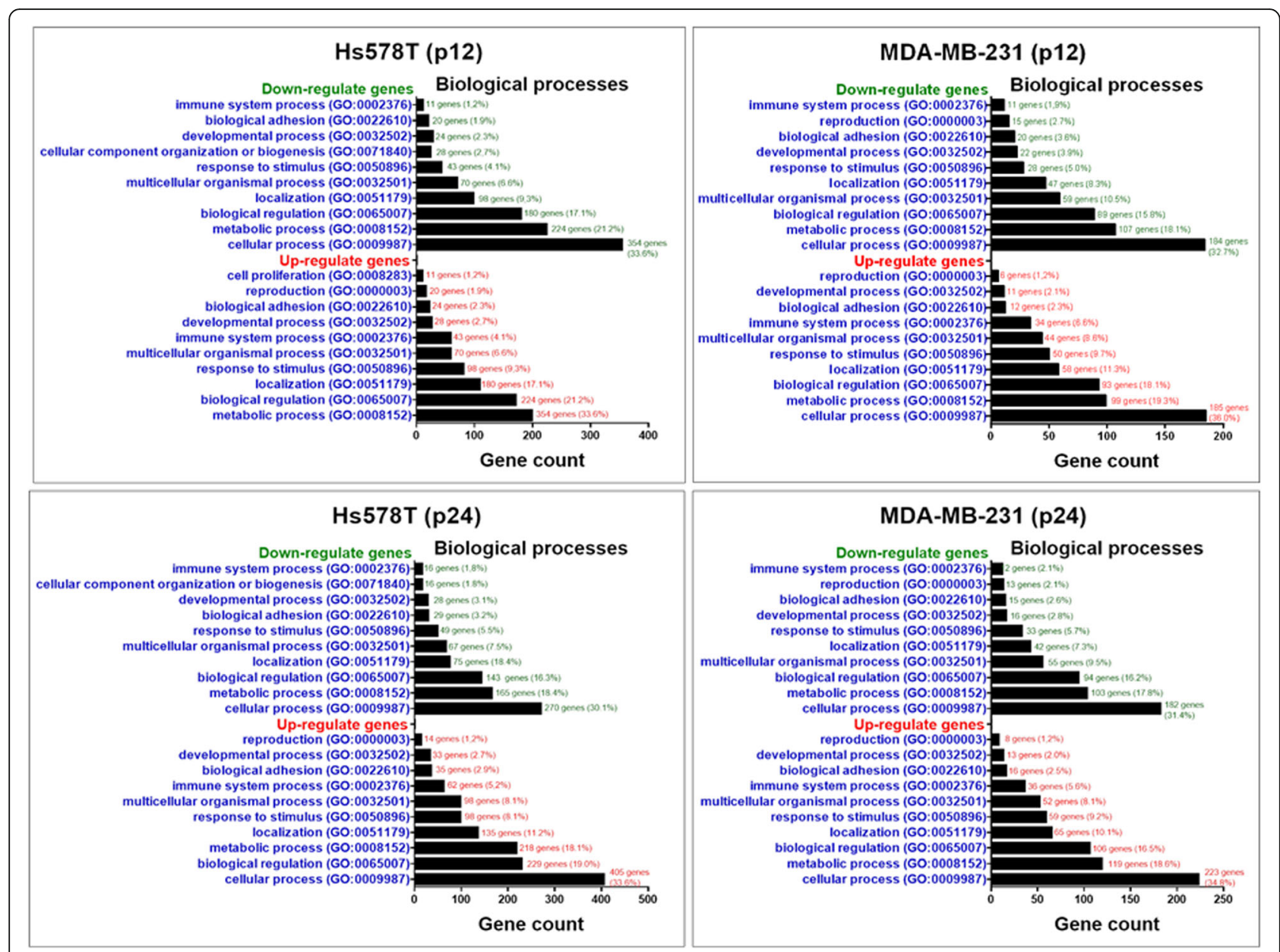

Fig. 6 The main biological processes specific for up- and downregulated altered genes in TNBC cell lines at P12 and P24 using Panther software (http://www.pantherdb.org)

$48 \mathrm{~h}$; the results are shown in Fig. 11. Was identified a minimally increased level of CXCL1, IL- 6 and TNF- $\alpha$ in the case of P12 and P24 versus parenteral cells, this effect being more intense in Hs578T than in MDA-MB231 cells.

\section{Discussions}

Doxorubicin remains one of the most active and used chemotherapeutic agent in the treatment of early and advanced breast cancer. Tumor resistance has limited the effectiveness of this therapeutic agent in single drug treatment regiments $[15,21]$. It is known that doxorubicin can induce drug resistance, but the most important aspect remains the exact mechanisms behind the resistance that is still poorly understood [22].

As an outcome, some biological processes are modified, including cellular state or adaptive response and chemotherapeutic tolerance, which are reflected through an increase of $\mathrm{IC}_{50}$ values at passage P12 and P24 for both cell lines. Also was observed the presence of modifications in the morphological traits and the presence of multinucleated giant cancer cells. This aspect was also found in literature, the frequency of giant cells being correlated with significant anticancer treatment alteration [23]. Other important alteration observed is related to the presence of stress fibers formation (Fig. 1), a mechanism necessary for EMT [24].

NGS is a very valuable tool used in disease characterization, as well as in cancer. Alterations in key genes can affect the response to therapy. In our study, we identified types of mutations involved in several cellular pathways. According to our NGS data, mutations occurred in TP53 gene were identified. TP53 is a gene that can be used as an independent prognostic factor and associated with a worse prognosis, but further investigation might be needed in order to predict the response to specific therapeutic agents [25]. In Hs578T cell line, TP53 c.215 C> G mutation is presented only in P12 and P24, meanwhile delGTG NOTCH1 c.4732_4734, a variant of unknown significance mutation was observed in P24. MDA-MB-231 cell 

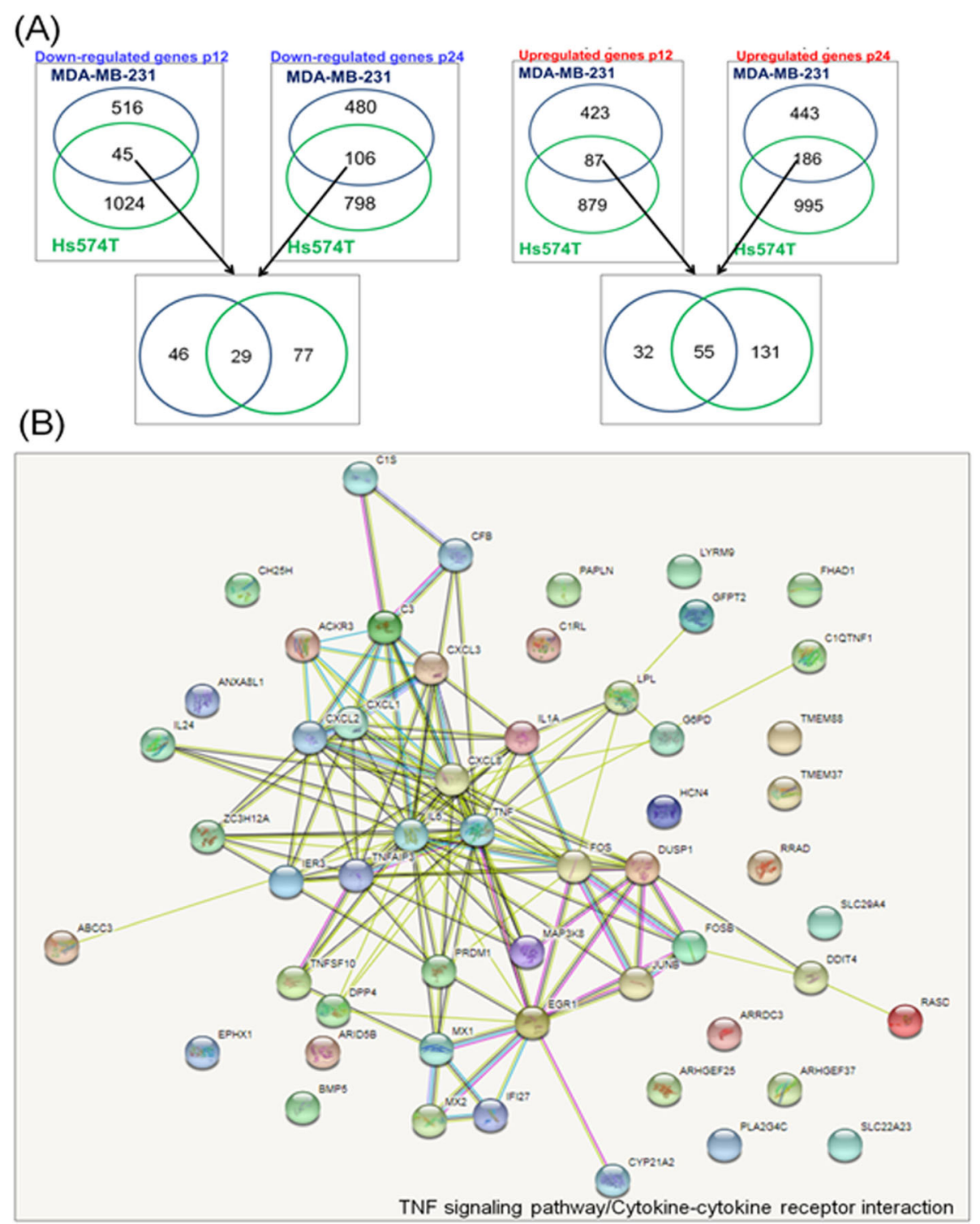

Fig. 7 Common altered signature as effect of multiple dose exposure to doxorubicine a Common altered up- and downregulated genes between P12 and P24 in Hs578T and MDA-MB-231. b Pathway analysis of differentially expressed genes at P12 and P24 on Hs578T and MDA-MB231 cell lines using String software

lines have pathogenic mutations in both passages, $\mathrm{P} 12$ and P24, A > G PIK3CA, drug response mutations $\mathrm{C}>\mathrm{G}$ TP53, as well as variant of unknown significance, $\mathrm{G}>\mathrm{A} K D R$, c."37delT CSF1A, c."35instA CSF1A, C > T SMAD4. These data show the in vitro effect of doxorubicin that can act deeply at the molecular level affecting the structure of DNA toward antitumoral effect.

Further, microarray data for coding and noncoding genes show a differential transcriptomics pattern between both cell lines as well as both passages (P12 and P24). Using bioinformatics tools, we found that most of the enriched GO terms were mainly common among the P12 and P24 for both cell lines treated with doxorubicin. GO analysis revealed that the differentially expressed genes were involved in cellular response, which can be an adaptive response mechanism to doxorubicin, sustained also by the comet assay data.

According to GOrilla software, an activation of the DNA binding activity was observed. This is a mechanism that is still under debate in the case of doxorubicin, but an important aspect is related to the chemoresistance process and correlated with TP53-deficient cell context [26]. The DNA damage might induce stabilization of tumor suppressor gene, TP53, and might affect cell cycle progression [26] or apoptosis related mechanisms via TNF $\alpha$ signaling (Fig. 7). Moreover, TNF- $\alpha$ was initially 


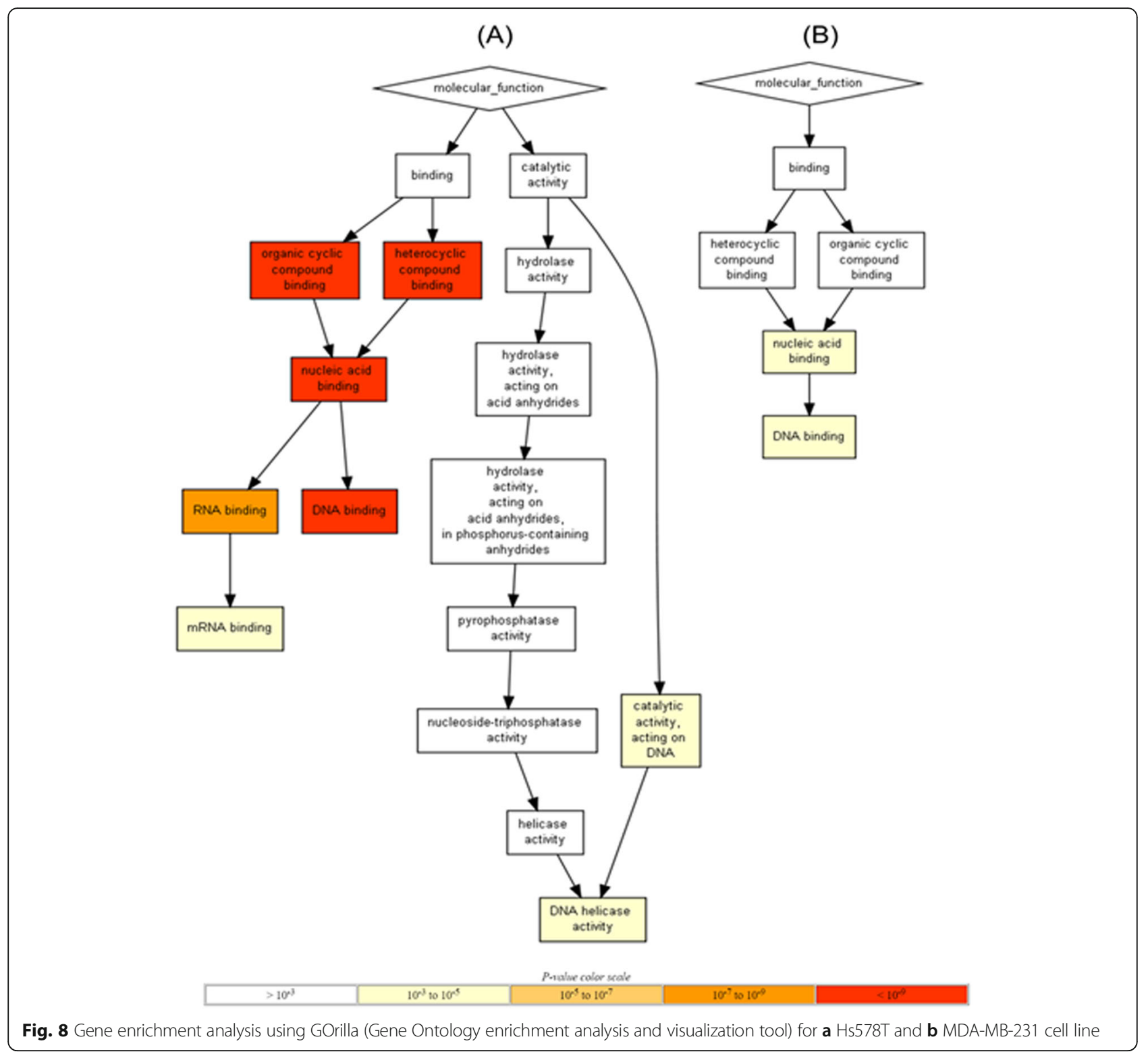

found to induce apoptosis in different cancer types by tumor-promoting activities including transformation, proliferation, invasion and metastasis of cancer cells [27]. A high level of TNF $\alpha$ is characteristic to breast cancer and has frequently been associated with a poor prognosis and an aggressive behavior [28]. TNF $\alpha$ has a particular role in enhancing migration and invasion in tumor cells, but the underlying mechanisms are still elusive $[29,30]$. In MDA-MB-231 cells was demonstrated that TNF- $\alpha$ increased the expression profile and activity of MMP-9 by inducing JUNB DNA binding activity, thus strengthening the concept of a pro-tumorigenic effect of TNF $\alpha$ in breast cancer [31]. Another process that involves TNF- $\alpha$ activity is the EMT, responsible for the loss of cell adhesion, disruption of cell-cell junctions, extensive actin cytoskeleton reorganization, resistance to cell death, increasing the mobility and invasiveness [32].

Doxorubicin acts as an intercalating agent having the ability to block DNA synthesis and transcription, as well as inhibiting the activity of topoisomerase type II enzyme. This process cause breaks in the genomic DNA that ultimately can lead to apoptosis [33]. These alterations induced in genomic DNA can lead to modifications responsible for the activation of critical biological processes, mainly involved in drug resistance [7]. In Fig. 8 are highlighted the main common genes involved in drug resistance mechanisms. The presence of ATPbinding cassette $(\mathrm{ABC})$ family transports suggest the implication and activation of the mechanisms involved in drug response. $A B C C 3$ and $A B C C 6$ members, which 


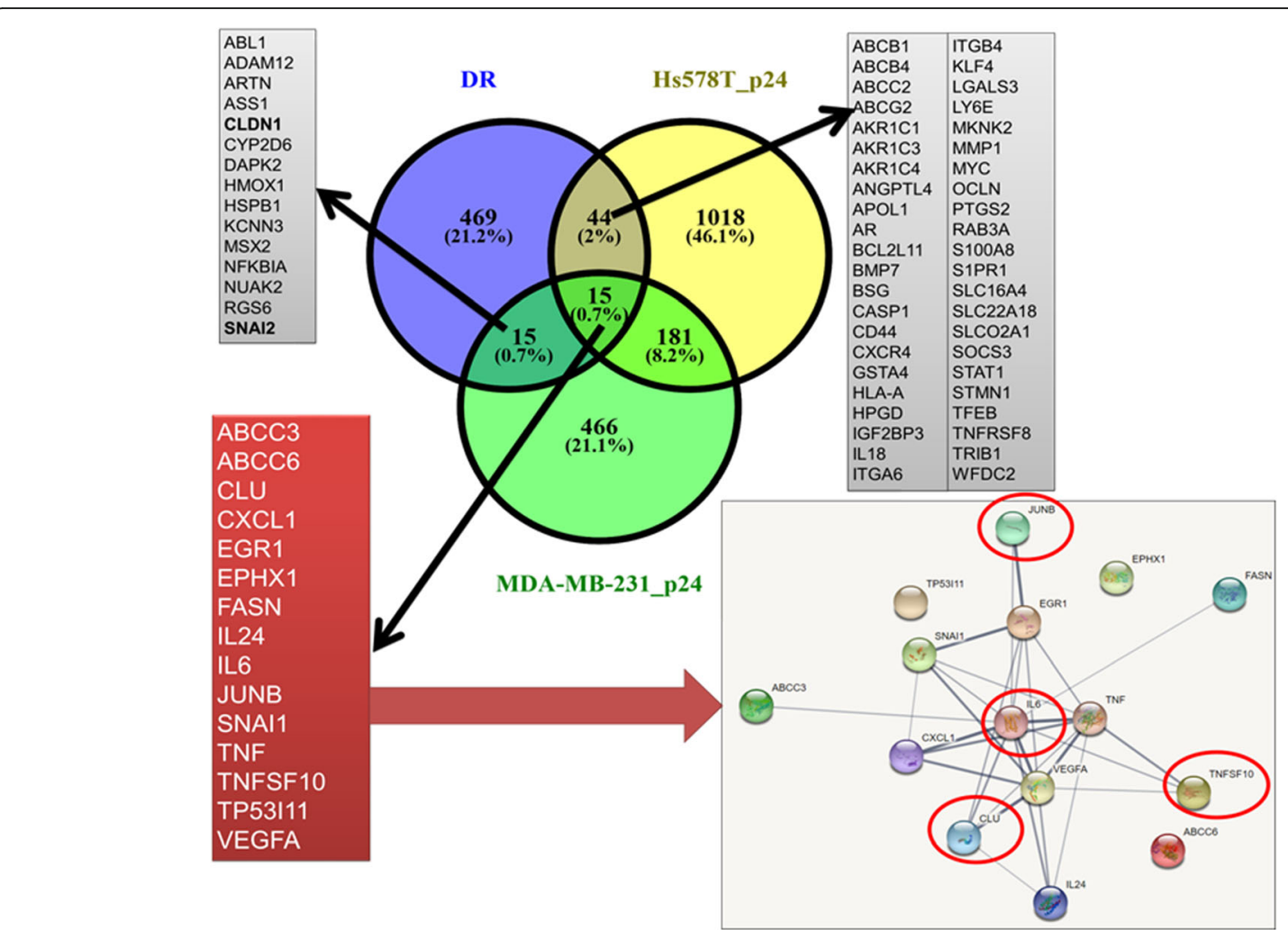

Fig. 9 Common drug resistance gene expression signature. a Venn diagram used to emphasis the common signature among the drug resistance gene list (downloaded from NCBI) and the overexpressed gene list at P24 on Hs578T and MBA-MB-231 cell lines. b Interaction network using String software for common genes signature involved in drug resistance mechanisms

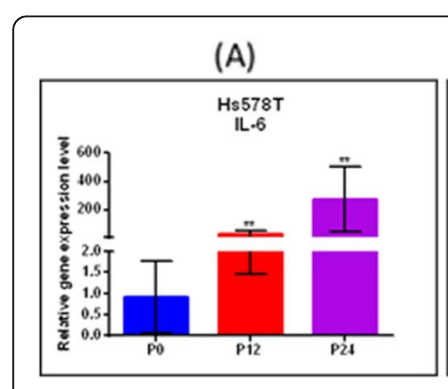

(E)

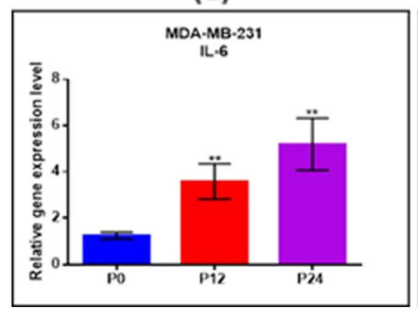

(B)

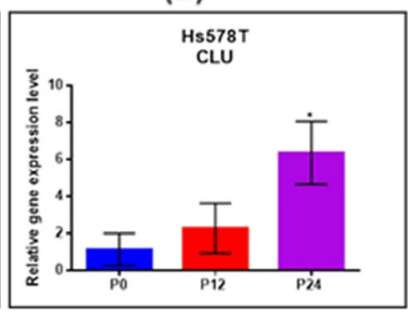

(F)

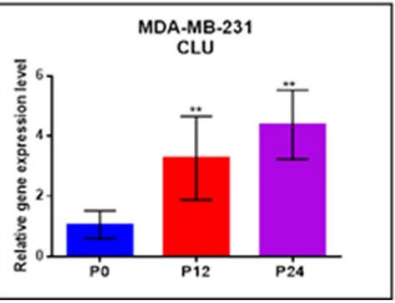

(C)

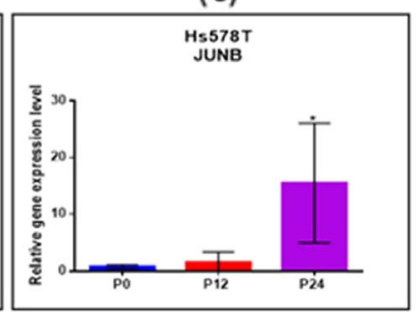

(G)

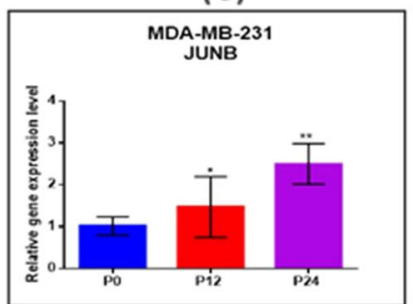

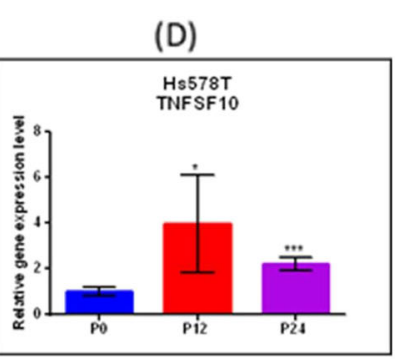

( $\mathrm{H})$

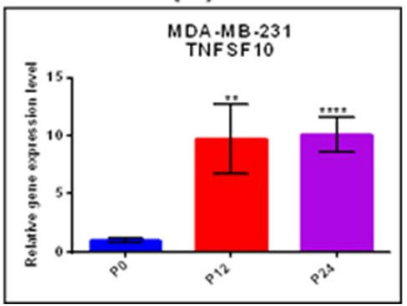

Fig. 10 Validation of the effect of doxorubicin therapy using RT-PCR technique on selected genes related to apoptosis processes. Relative gene expression levels are shown for IL-6, CLU, JUNB, TNFSF10 in treated and untreated group, between P12 and P24 versus P0 on Hs578T and MDA_MB-231 cell lines. The data were normalized to GAPDH and B2M using $\triangle \Delta \mathrm{C}_{\mathrm{T}}$ method. Data are presented as mean \pm SD using two-sided t-test 

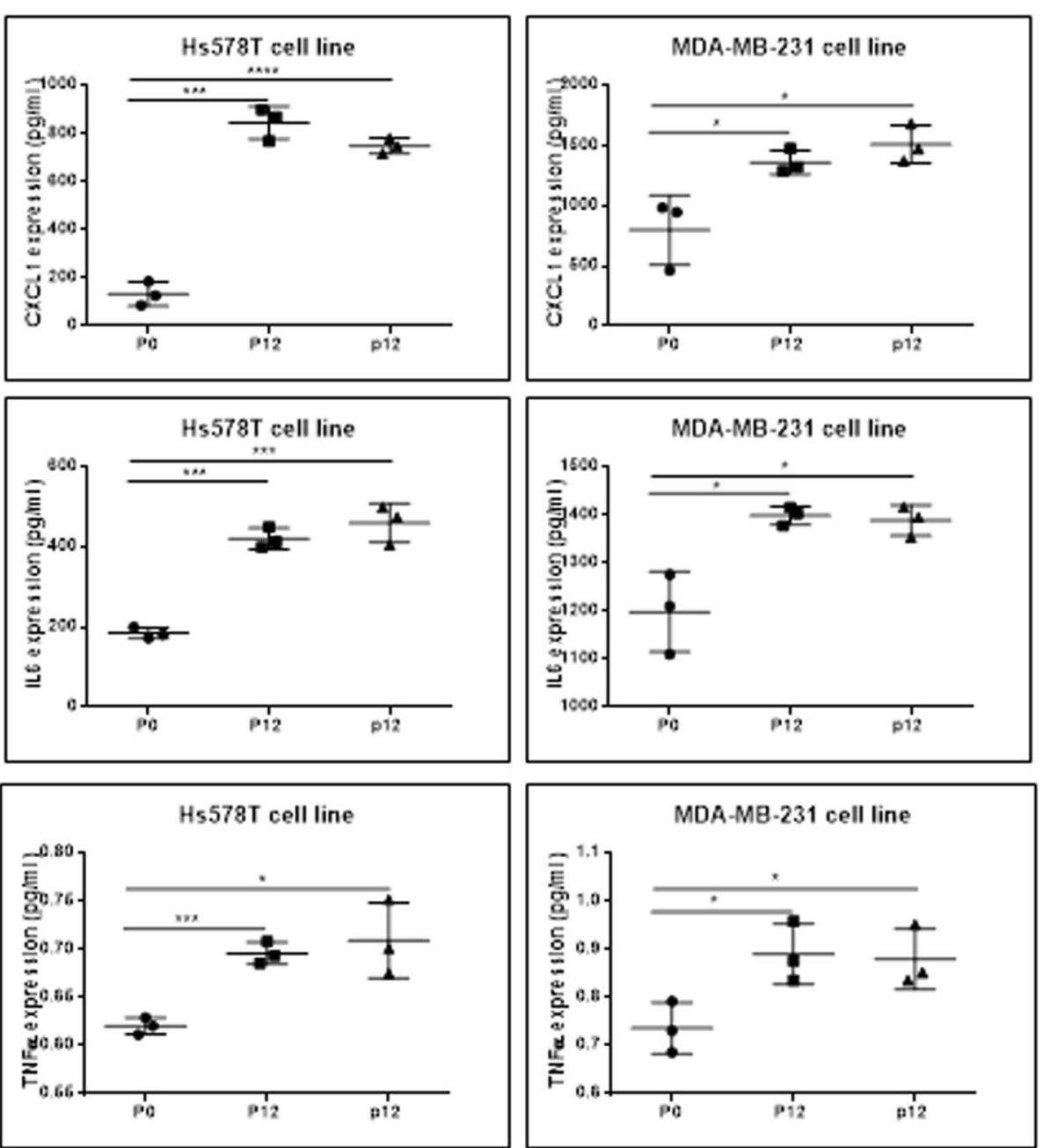

Fig. 11 Evaluation of the CXCL1, IL-6 and TNF-a released in cell culture medium by ELISA, for parenteral cells (P0), P12 and P24 for Hs578T and MBA-MB-231 cell lines

participate directly in the active transport of drugs into subcellular organelles or influence drug distribution indirectly, were observed in our study. Balaji et al. showed that overexpression of $A B C C 3$ is correlated with decreased drug retention; meanwhile knockdown of $A B C C 3$ increased drug retention and cell death [34]. Overexpression of $A B C C 6$ is able to confer low levels of resistance to several anticancer agents including doxorubicin, etoposide, daunorubicin and actinomycin [35]. Other gene found in drug resistance network is JUNB which has been associated with invasion/metastasis in breast cancer and represents an important target in diseases, associated with EMT. Also, JUNB has been involved in the earliest events of resistance development in breast cancer [36]. In addition, CLU (Clusterin) is involved in anti-apoptotic processes, development of therapy resistance, induction of EMT, all associated with cancer metastasis. Moreover, $C L U$ has the capability to protect metastatic cells from cell death, leading to cell survival in different environment
[37]. Also, CLU is a stress-activated cytoprotective chaperone targeted and upregulated by a wide range of anticancer therapies that confer treatment resistance [38]. In breast cancer, overexpression of $C L U$ was also associated with resistance to neoadjuvant chemotherapy [39].

The significant altered gene expression signature identified can reflect biological regulation and metabolic response in the presence of doxorubicin. We found that TNBC cells developed an adaptive response against the intracellular stress induced by doxorubicin therapy during the stimulation of the resistance process. We identified a 15 gene common signature (TNF, VEGFA, IL-6, TNFSF10, CLU, ABCC6, EGR1, SNAI1, ABCC3, EPHX1, FASN, CXCL1, IL24, JUNB, TP53I11) correlated with drug resistance.

\section{Conclusion}

By understanding the molecular bases of chemoresistance in TNBC and functional pathways that are involved in drug resistance mechanisms, we tried to reveal 
critical aspects to improve prognosis rate and to counteract drug resistance mechanisms. Our study provided important information related to doxorubicin response mechanism correlating data of genetic and transcriptomic alteration with gene networks associated with drug resistance and cellular response. This information could be a valuable starting point for follow-up experiments that might test novel drug targets for anti-cancer treatment in order to prevent activation of drug resistance mechanisms.

\section{Supplementary Information}

Supplementary information accompanies this paper at https://doi.org/10. 1186/s13046-020-01736-2.

Additional file 1: Figure S1. The experimental workflow for the multiple dose exposure, at each 4 days cells were passaged and added fresh medium with $50 \mathrm{~nm}$ Dox.

\section{Competing interests}

Authors have no financial and non-financial competing interests be declared related to this paper.

\section{Author details}

${ }^{1}$ Research Center for Functional Genomics, Biomedicine and Translational Medicine, "Iuliu Hatieganu" University of Medicine and Pharmacy, Cluj-Napoca, Romania. ${ }^{2}$ MedFuture Research Center for Advanced Medicine, "Iuliu Hatieganu" University of Medicine and Pharmacy, Cluj-Napoca, Romania. ' 2 Laboratory of Radiotherapy, Radiobiology and Tumor Biology, "Prof. Dr. Ion Chiricuta" Oncology Institute, Cluj-Napoca, Romania. ${ }^{4}$ Department of Surgical Oncology and Gynecological Oncology, "Iuliu Hatieganu" University of Medicine and Pharmacy, Cluj-Napoca, Romania. ${ }^{5}$ Department of Surgery, "Prof. Dr. Ion Chiricuta" Oncology Institute, Cluj-Napoca, Romania. 'Brazilian Biosciences National Laboratory (LNBio), Brazilian Center for Research in Energy and Materials (CNPEM), Campinas, Sao Paulo 13083-970, Brazil. 'Department of Functional Genomics and Experimental Pathology, "Prof. Dr. Ion Chiricuta" Oncology Institute, Cluj-Napoca, Romania.

Received: 10 June 2020 Accepted: 14 October 2020

Published online: 13 November 2020

\section{References}

1. Hudis CA, Gianni L. Triple-negative breast cancer: an unmet medical need. Oncologist. 2011;16(Suppl 1):1-11. https://doi.org/10.1634/theoncologist. 2011-S1-01.

2. Braicu C, Raduly L, Morar-Bolba G, Cojocneanu R, Jurj A, Pop LA, Pileczki V, Ciocan C, Moldovan A, Irimie A, Eniu A, Achimas-Cadariu P, Paradiso A, et al. Aberrant miRNAs expressed in HER-2 negative breast cancers patient. J Exp Clin Cancer Res. 2018;37:257. https://doi.org/10.1186/s13046-018-0920-2.

3. Tormo E, Ballester $S$, Adam-Artigues A, Burgués O, Alonso E, Bermejo B, Menéndez S, Zazo S, Madoz-Gúrpide J, Rovira A, Albanell J, Rojo F, Lluch A, et al. The miRNA-449 family mediates doxorubicin resistance in triplenegative breast cancer by regulating cell cycle factors. Scientific Rep. 2019;9: 5316. https://doi.org/10.1038/s41598-019-41472-y.

4. Lajos R, Braicu C, Jurj A, Chira S, Cojocneanu-Petric R, Pileczki V, BerindanNeagoe I. A miRNAs profile evolution of triple negative breast cancer cells in the presence of a possible adjuvant therapy and senescence inducer. J Buon. 2018;23:692-705.

5. Braicu C, Chiorean R, Irimie A, Chira S, Tomuleasa C, Neagoe E, Paradiso A, Achimas-Cadariu P, Lazar V, Berindan-Neagoe I. Novel insight into triplenegative breast cancers, the emerging role of angiogenesis, and antiangiogenic therapy. Expert Rev Mol Med. 2016;18:e18. https://doi.org/10. 1017/erm.2016.17

6. Pileczki V, Pop L, Braicu C, Budisan L, Bolba Morar G, Del CM-BP, Sandulescu RV, Berindan-Neagoe I. Double gene siRNA knockdown of mutant p53 and TNF induces apoptosis in triple-negative breast cancer cells. Onco Targets Ther. 2016;9:6921-33. https://doi.org/10.2147/ott.S110719.

7. Duan Z, Duan Y, Lamendola DE, Yusuf RZ, Naeem R, Penson RT, Seiden MV Overexpression of MAGE/GAGE genes in paclitaxel/doxorubicin-resistant human cancer cell lines. Clin Cancer Res. 2003;9(7):2778-85.

8. Krausz AE, Adler BL, Makdisi J, Schairer D, Rosen J, Landriscina A, Navati M, Alfieri A, Friedman JM, Nosanchuk JD, Rodriguez-Gabin A, Ye KQ, McDaid HM, et al. Nanoparticle-encapsulated doxorubicin demonstrates superior tumor cell kill in triple negative breast cancer subtypes intrinsically resistant to doxorubicin. Precision Nanomed. 2018;1:173-82. https://doi.org/10.33218/ prnano1(3).181029.1

9. Chiorean R, Braicu C, Berindan-Neagoe I. Another review on triple negative breast cancer. Are we on the right way towards the exit from the labyrinth? Breast. 2013;22:1026-33. https://doi.org/10.1016/j.breast.2013.08.007.

10. Marinello PC, Panis C, Silva TNX, Binato R, Abdelhay E, Rodrigues JA, Mencalha AL, Lopes NMD, Luiz RC, Cecchini R, Cecchini AL. Metformin prevention of doxorubicin resistance in MCF-7 and MDA-MB-231 involves oxidative stress generation and modulation of cell adaptation genes. Sci Rep. 2019;9:5864. https://doi.org/10.1038/s41598-019-42357-w.

11. Ciocan-Cârtiță CA, Jurj A, Raduly L, Cojocneanu R, Moldovan A, Pileczki V, Pop LA, Budişan L, Braicu C, Korban SS, Berindan-Neagoe I. New perspectives in triple-negative breast cancer therapy based on treatments with TGF $\beta 1$ siRNA and doxorubicin. Mol Cell Biochem. 2020. https://doi.org/ 10.1007/s11010-020-03881-w.

\section{Consent for publication}

Not applicable. 
12. Han J, Lim W, You D, Jeong Y, Kim S, Lee JE, Shin TH, Lee G, Park S. Chemoresistance in the human triple-negative breast cancer cell line MDAMB-231 induced by doxorubicin gradient is associated with epigenetic alterations in histone deacetylase. J Oncol. 2019;2019:1345026. https://doi. org/10.1155/2019/1345026.

13. Pop-Bica C, Gulei D, Cojocneanu-Petric R, Braicu C, Petrut B, BerindanNeagoe I. Understanding the role of non-coding RNAs in bladder Cancer: from dark matter to valuable therapeutic targets. Int J Mol Sci. 2017;18. https://doi.org/10.3390/ijms18071514.

14. Jurj A, Pop LA, Zanoaga O, Ciocan-Cârtiță CA, Cojocneanu R, Moldovan C, Raduly L, Pop-Bica C, Trif M, Irimie A, Berindan-Neagoe I, Braicu C. New insights in gene expression alteration as effect of paclitaxel drug resistance in triple negative breast cancer cells. Cell Physiol Biochem. 2020;54:648-64. https://doi.org/10.33594/000000246.

15. Parca L, Pepe G, Pietrosanto M, Galvan G, Galli L, Palmeri A, Sciandrone M, Ferrè F, Ausiello G, Helmer-Citterich M. Modeling cancer drug response through drug-specific informative genes. Sci Rep. 2019;9:15222. https://doi. org/10.1038/s41598-019-50720-0.

16. Perde-Schrepler M, Fischer-Fodor E, Virag P, Brie I, Cenariu M, Pop C, Valcan A, Gurzau E, Maniu A. The expression of copper transporters associated with the ototoxicity induced by platinum-based chemotherapeutic agents. Hear Res. 2020;388:107893. https://doi.org/10.1016/j.heares.2020.107893.

17. Belmans N, Gilles L, Vermeesen R, Virag P, Hedesiu M, Salmon B, Baatout S, Lucas S, Lambrichts I, Jacobs R, Moreels M. Quantification of DNA double Strand breaks and oxidation response in children and adults undergoing dental CBCT scan. Sci Rep. 2020;10:2113. https://doi.org/10.1038/s41598-02058746-5.

18. Goidescu IG, Caracostea G, Eniu DT, Stamatian FV. Prevalence of deleterious mutations among patients with breast cancer referred for multigene panel testing in a Romanian population. Clujul Med (1957). 2018;91:157-65. https://doi.org/10.15386/cjmed-894.

19. Li G, Guo X, Chen M, Tang L, Jiang H, Day JX, Xie Y, Peng L, Xu X, Li J, Wang $S$, Xiao Z, Dai L, et al. Prevalence and spectrum of AKT1, PIK3CA, PTEN and TP53 somatic mutations in Chinese breast cancer patients. PloS One. 2018;13:e0203495-e. https://doi.org/10.1371/journal.pone.0203495.

20. Paulo P, Maia S, Pinto C, Pinto P, Monteiro A, Peixoto A, Teixeira MR. Targeted next generation sequencing identifies functionally deleterious germline mutations in novel genes in early-onset/familial prostate cancer. PLoS Genet. 2018;14:e1007355-e. https://doi.org/10.1371/journal.pgen. 1007355.

21. Lovitt CJ, Shelper TB, Avery VM. Doxorubicin resistance in breast cancer cells is mediated by extracellular matrix proteins. BMC Cancer. 2018;18:41. https:// doi.org/10.1186/s12885-017-3953-6.

22. Christowitz C, Davis T, Isaacs A, van Niekerk G, Hattingh S, Engelbrecht A-M. Mechanisms of doxorubicin-induced drug resistance and drug resistant tumour growth in a murine breast tumour model. BMC Cancer. 2019;19:757. https://doi.org/10.1186/s12885-019-5939-z.

23. Mirzayans R, Andrais B, Murray D. Roles of Polyploid/multinucleated Giant Cancer cells in metastasis and disease relapse following anticancer treatment. Cancers. 2018;10:118. https://doi.org/10.3390/ cancers 10040118 .

24. Haynes J, Srivastava J, Madson N, Wittmann T, Barber DL. Dynamic actin remodeling during epithelial-mesenchymal transition depends on increased moesin expression. Mol Biol Cell. 2011;22:4750-64. https://doi.org/10.1091/ mbc.E11-02-0119.

25. J-p L, X-m Z, Zhang Z, Zheng L-h, Jindal S, Liu Y-j. Association of p53 expression with poor prognosis in patients with triple-negative breast invasive ductal carcinoma. Medicine. 2019;98:e15449. https://doi.org/10. 1097/md.0000000000015449.

26. Dalmases A, Gonzalez I, Menendez S, Arpi O, Corominas JM, Servitja S, Tusquets I, Chamizo C, Rincon R, Espinosa L, Bigas A, Eroles P, Furriol J, et al. Deficiency in p53 is required for doxorubicin induced transcriptional activation of NF-small ka, CyrillicB target genes in human breast cancer. Oncotarget. 2014;5:196-210. https://doi.org/10.18632/oncotarget.1556.

27. Waters JP, Pober JS, Bradley JR. Tumour necrosis factor and cancer. J Pathol. 2013;230:241-8. https://doi.org/10.1002/path.4188.

28. Wolczyk D, Zaremba-Czogalla M, Hryniewicz-Jankowska A, Tabola R, Grabowski K, Sikorski AF, Augoff K. TNF-a promotes breast cancer cell migration and enhances the concentration of membrane-associated proteases in lipid rafts. Cell Oncol (Dordr). 2016;39:353-63. https://doi.org/ $10.1007 / \mathrm{s} 13402-016-0280-\mathrm{x}$
29. Katerinaki E, Evans GS, Lorigan PC, MacNeil S. TNF-alpha increases human melanoma cell invasion and migration in vitro: the role of proteolytic enzymes. Br J Cancer. 2003;89:1123-9. https://doi.org/10.1038/sj.bjc.6601257.

30. Wu Y, Zhou BP. TNF-alpha/NF-kappaB/snail pathway in cancer cell migration and invasion. Br J Cancer. 2010;102:639-44. https://doi.org/10. 1038/sj.bjc.6605530.

31. Kim S, Choi JH, Kim JB, Nam SJ, Yang JH, Kim JH, Lee JE. Berberine suppresses TNF-alpha-induced MMP-9 and cell invasion through inhibition of AP-1 activity in MDA-MB-231 human breast cancer cells. Molecules. 2008; 13:2975-85. https://doi.org/10.3390/molecules13122975.

32. Martínez-Reza I, Díaz L, García-Becerra R. Preclinical and clinical aspects of TNF- $a$ and its receptors TNFR1 and TNFR2 in breast cancer. J Biomed Sci. 2017;24:90. https://doi.org/10.1186/s12929-017-0398-9.

33. Aghaee F, Islamian JP, Baradaran B, Mesbahi A, Mohammadzadeh M, Jafarabadi MA. Enhancing the effects of low dose doxorubicin treatment by the radiation in T47D and SKBR3 breast Cancer cells. J Breast Cancer. 2013; 16:164-70. https://doi.org/10.4048/jbc.2013.16.2.164.

34. Balaji SA, Udupa N, Chamallamudi MR, Gupta V, Rangarajan A. Role of the drug transporter ABCC3 in breast Cancer Chemoresistance. PLoS One. 2016; 11:e0155013. https://doi.org/10.1371/journal.pone.0155013.

35. Arányi T, Bacquet $C$, de Boussac H, Ratajewski M, Pomozi V, Fülöp K, Brampton CN, Pulaski L, Le Saux O, Váradi A. Transcriptional regulation of the $A B C C 6$ gene and the background of impaired function of missense disease-causing mutations. Front Genet. 2013;4:27. https://doi.org/10.3389/ fgene.2013.00027.

36. Kallergi G, Tsintari V, Sfakianakis S, Bei E, Lagoudaki E, Koutsopoulos A Zacharopoulou N, Alkahtani S, Alarifi S, Stournaras C, Zervakis M, Georgoulias V. The prognostic value of JUNB-positive CTCs in metastatic breast cancer: from bioinformatics to phenotypic characterization. Breast Cancer Res. 2019;21:86. https://doi.org/10.1186/s13058-019-1166-4.

37. Zhang H, Kim JK, Edwards CA, Xu Z, Taichman R, Wang CY. Clusterin inhibits apoptosis by interacting with activated Bax. Nat Cell Biol. 2005;7:909-15. https://doi.org/10.1038/ncb1291.

38. Peng M, Deng J, Zhou S, Tao T, Su Q, Yang X, Yang X. The role of Clusterin in cancer metastasis. Cancer Manag Res. 2019;11:2405-14. https://doi.org/10. 2147/cmar.S196273

39. Niu ZH, Wang Y, Chun B, Li CX, Wu L. Secretory clusterin (sCLU) overexpression is associated with resistance to preoperative neoadjuvant chemotherapy in primary breast cancer. Eur Rev Med Pharmacol Sci. 2013; 17:1337-44.

\section{Publisher's Note}

Springer Nature remains neutral with regard to jurisdictional claims in published maps and institutional affiliations.
Ready to submit your research? Choose BMC and benefit from:

- fast, convenient online submission

- thorough peer review by experienced researchers in your field

- rapid publication on acceptance

- support for research data, including large and complex data types

- gold Open Access which fosters wider collaboration and increased citations

- maximum visibility for your research: over $100 \mathrm{M}$ website views per year

At $\mathrm{BMC}$, research is always in progress.

Learn more biomedcentral.com/submissions 